
$\angle$ Research Square
Preprints are preliminary reports that have not undergone peer review.
They should not be considered conclusive, used to inform clinical practice, or referenced by the media as validated information.

\title{
High Occupational Physical Activity and cardiovascular risk factors in employees: a cross-sectional study
}

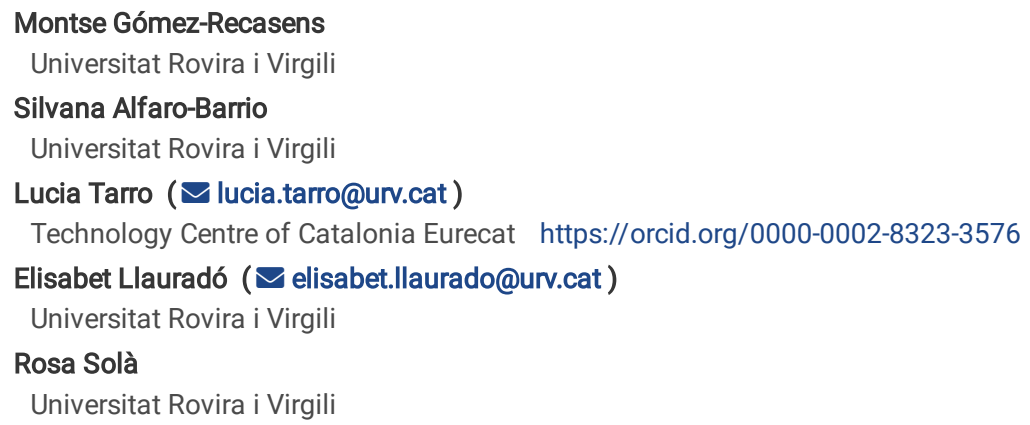




\section{Abstract}

Background

The impact of occupational physical activity (OPA) intensity, considering adults work many hours a day, on health is unknown. The present study aims to evaluate the association between the high intensity of OPA and cardiovascular risk factors of employees.

Methods

A cross-sectional study was carried out in the "Fomento de Construcciones y Contratas S.A. Company" (FCC S.A. Delegation) in 2017, Spain. The intensity of OPA of each employee was classified by work categories in low ( $\leq 3 \mathrm{METs}$ ) or high ( $>3 \mathrm{METs})$. Health and lifestyle data of employees were collected on medical consultation in the workplace.

Results

Associations were analyzed between the high intensity of OPA and cardiovascular risk factors of employees. 751 employees, $55.5 \%(n=417)$ with high intensity of OPA. An $82.2 \%(n=245)$ of employees with low intensity of OPA presented overweight/obesity compared with $69.0 \%(n=171)$ with high intensity of OPA employees $(p<0.001)$. In men, high intensity of OPA is negatively associated with Body Mass Index (BMI) (B: $-0.042, p=0.003)$, waist circumference (B: $-0.027, p<0.001)$ waist-hip ratio $(B:-5.484, p<0.001)$, cholesterol $(B:-0.007, p=0.001)$ and triglycerides $(B=-0.003, p=0.025)$. In women, high intensity of $0 P A$ was positively associated with blood pressure $(B P)$ (systolic $B P: B=0.036, p=0.005$ and diastolic $B P: B=0.040, p=0.021$ ).

Conclusions

In conclusion, the high intensity of OPA is associated with less cardiovascular risk factors in men, whereas women are associated with high levels of blood pressure, suggesting an influence of gender and work categories.

\section{Background}

Workplace has been identified as a suitable environment to promote healthy lifestyles to prevent chronic diseases [1], due to the large population involved and prolonged periods of working days [2, 3].

Lifestyles, such as leisure-time physical activity (LTPA), decrease the risk of some chronic diseases as cardiovascular disease, obesity, diabetes mellitus, hypertension and some types of cancer [4-6].

The interesting, high time of LTPA, without considering the intensity, are inversely associated with the prevalence of the cardiovascular disease in males and females [7].

However, the impact of high intensity of occupational physical activity (OPA) on health remains unknown with the evidence published up to now. The OPA intensity could have an impact on cardiovascular disease, the leading cause of death in the world [8]. Whereas low intensity of OPA is few or no-associated with poor health status, as a higher risk for stroke, specifically in women $[9,10]$, high levels of OPA are associated with an increased risk of mortality in men but decreased the risk of mortality in women, from a meta-analysis of prospective studies data [11]. Therefore, physical activity has paradoxical health effects depending on if this physical activity is developed over leisure (LTPA) or occupational time (OPA) [12] which could be explained due to high intensity of OPA performed over long periods with insufficient recovery time, leading can cause a sustained inflammation, one of the hypothesized pathways in the etiology of cardiovascular diseases $[13,14]$.

Thus, the association between high OPA intensity and cardiovascular risk factors needs to be confirmed.

Fomento de Construcciones y Contratas (FCC) S.A. is a Spanish company with a great experience delivering services to citizens all over the world. FCC S.A. has the Catalonia Delegation II (Tarragona and Lleida provinces) of the environmental area (hereafter, the FCC S.A. Delegation) with employees with different OPA intensities who could be evaluated by impact of OPA.

The present study aims to evaluate the association between the high intensity of OPA and cardiovascular risk factors of employees (18-65 years old) of the FCC S.A. Delegation.

\section{Methods}

\section{Design and setting of the study}

This study is a cross-sectional study carried out from 1 January to 31 December 2017 in the FCC S.A. Delegation. All employers and employees have signed written informed consent. The study design was approved and agreed by the security and health committees of all company worksites and signed with the worksite unions, and it was included in the collective bargaining agreement and obtained a certificate of ethical approval from the Security and Health Committee of the FCC S.A. Delegation and the Catalan public administration. The present cross-sectional study follows the STROBE criteria [15] (additional file 1).

\section{Inclusion and exclusion criteria}


To be eligible for inclusion, participants had to 1) be an employee of the FCC S.A. Delegation company with at least one year of service, 2 ) be $\geq 18$ years old to 65 years old, and 3) have a medical visit in 2017. The exclusion criteria were noncompliance with an inclusion criterion.

\section{Data collection}

In FCC S.A. Delegation Medical Examination Service, the physician did a check-up of all employees every year and recruited the information of employees in the workplace such as age, gender, anthropometric, biochemical, and lifestyle.

This medical visit consisted of the recruitment of anthropometric, biochemical and lifestyle data.

\section{Anthropometric data}

Anthropometric data were weight $(\mathrm{kg})$, height $(\mathrm{m})$ and waist circumference (WC) measured above the iliac crest and hip circumference (HP) (cm) using the Lohman manual [16].Diagnoses of abdominal obesity were assessed (WC $\geq 102 \mathrm{~cm}$ in men and $\geq 88 \mathrm{~cm}$ in women) [17, 18]. The waist-hip ratio was calculated by dividing WC by HC (considered high waist-hip ratio for men $>1$ and women $>0.9031)$ [17]. Moreover, body mass index $(\mathrm{BMI})\left(\mathrm{kg} / \mathrm{m}^{2}\right)$ was calculated, and it was categorized using the World Health Organization (WHO) thresholds (BMI $\geq 25 \mathrm{~kg} / \mathrm{m}^{2}$ overweight or $\geq 30 \mathrm{~kg} / \mathrm{m}^{2}$ obesity).

Systolic and diastolic blood pressure were collected $(\mathrm{mmHg})$ using the OMRON $\circledast$ arterial pressure monitor. The employees were sitting in at rest for about 10 minutes with the arterial pressure monitor in the arm, the physician measured three times the arterial pressure and the mean of three measurements were used. The hypertensive employees were registered in the medical record and were register for the prescribed medication for hypertension by family physicians for obtaining more information about the employee.

\section{Biochemical data}

Biochemical data were parameters related to cardiovascular diseases: cholesterol, triglycerides, and glucose collected in blood samples. Employees with hypercholesterolemia (cholesterol $\geq 200 \mathrm{mg} / \mathrm{dL}$ ), hypertriglyceridemia (triglycerides $\geq 150 \mathrm{mg} / \mathrm{dL}$ ), and diabetes mellitus ( $\mathrm{glucose} \geq 126 \mathrm{mg} / \mathrm{dL}$ ) were derived from a family physician, to obtain better health management of the employee.

\section{Lifestyle data}

Focusing on lifestyle, alcohol risky consumption was considered if the employed referred an alcohol consumption > 28 standard drink units (SDUs) /week in males and 17 SDUs/week in females. Tobacco consumption was registered if the employee is an active smoker. Physical activity outside of work hours (named as leisure-time physical activity, LTPA) were collected by International Physical Activity Questionnaire [19] and classified by $\geq 30$ minutes/day of LTPA as high LTPA or < 30 minutes/day of LTPA as low LTPA. From this questionnaire [19], it was only considered LTPA, but other variables such as transport used, household domain and working hours were dismissed.

\section{Employees OPA and socioeconomic characteristics}

Employees were classified by different work categories based on the International Labour Organization [20], and linked with socioeconomic level evaluated [21, 22], into:

a) Managers: administrative and commercial managers/production and specialized service managers (high socioeconomic levels: directors and managers),

b) Drivers and mobile plant operators (medium socioeconomic level: intermediate occupation),

c) Supervisor of operators and drivers (medium socioeconomic level: intermediate occupation),

d) Cleaners and helpers (low and very low socioeconomic level: primary qualified, half-qualified and non-qualified), and,

e) Plant and machine operators and assemblers (low and very low socioeconomic level: primary qualified,half-qualified and non-qualified).

Moreover, the intensity of OPA was registered from the Compendium of Physical Activities [23] and work categories by the International Labour Organization [20]. The OPA intensity was the physical activity developed in the workplace, and this is assessed by physical activity intensity done during work hours using METs, depending on the type of work. Employees who spent $\leq 3$ METs in their work hours per day were categorized as the low intensity of OPA, and employees who spent > 3 METs in their work hours per day were categorized as the high intensity of OPA.

\section{Additional data}

The Metabolic Syndrome of employees has considered if they present these three factors: diabetes mellitus, hypercholesterolemia, obesity and/or hypertension and its association with OPA intensity [24]

\section{Sample size}

From 19,471 employees in Spain at 2019 (Instituto Nacional de Estadística., 2019), it was calculated a sample size to estimate with a 95\% confidence interval (Cl) and a precision of \pm 5 percent with cardiovascular risk factors, considering in Spain around $46 \%$ of employees presented cardiovascular risk factors, [26], 467 employees will suffice. It is being anticipated the replacement rate of $20 \%$.

\section{Statistical analyses}


The principal outcome was the association of OPA intensity calculated by the physical activity of the category work of each employee and cardiovascular risk factors. The secondary outcome was considered the association of OPA intensity and cardiovascular risk factors segregated by gender.

Continuous variables were presented as the means \pm standard deviations (SD), and categorical variables are presented as percentages. ANOVA test was used to compare continuous variables and Chi-square to compare categorical variables. Analyses were conducted segregating the population by OPA intensity and gender. Logistic regression models were used to analyze the associations between OPA and cardiovascular risk factors. Logistic regression multivariate analysis was used to calculate the associations with high intensity of OPA and anthropometric or biochemical parameters, whereas for categorical variables such as lifestyle parameters (tobacco and alcohol consumption, it used binary regression logistic analysis to calculate the association with high intensity of OPA).

All data were analyzed using SPSS V.25.0 for Windows (SPSS Inc., Chicago, Illinois, USA). The level of statistical significance was set to $p<0.05$.

\section{Results}

All of the employees, 751 employees from the FCC S.A. Delegation were included in the present cross-sectional study.

Table 1 showed the characteristics of the FCC S.A. Delegation, consisted mainly of males $(72.7 \%(n=546 / 751))$. The age mean $\pm($ SD) of the total population was $45.2 \pm 9.8$ years. A $98.8 \%(n=742)$ of the FCC S.A. Delegation employees had a low or very low socioeconomic level according to the work categories of employees; highlighting that a $51.7 \%$ of employees were non-qualified workers (categorized as very low socioeconomic employees).

Table 1

Characteristics of worker population of the FCC S.A. Delegation

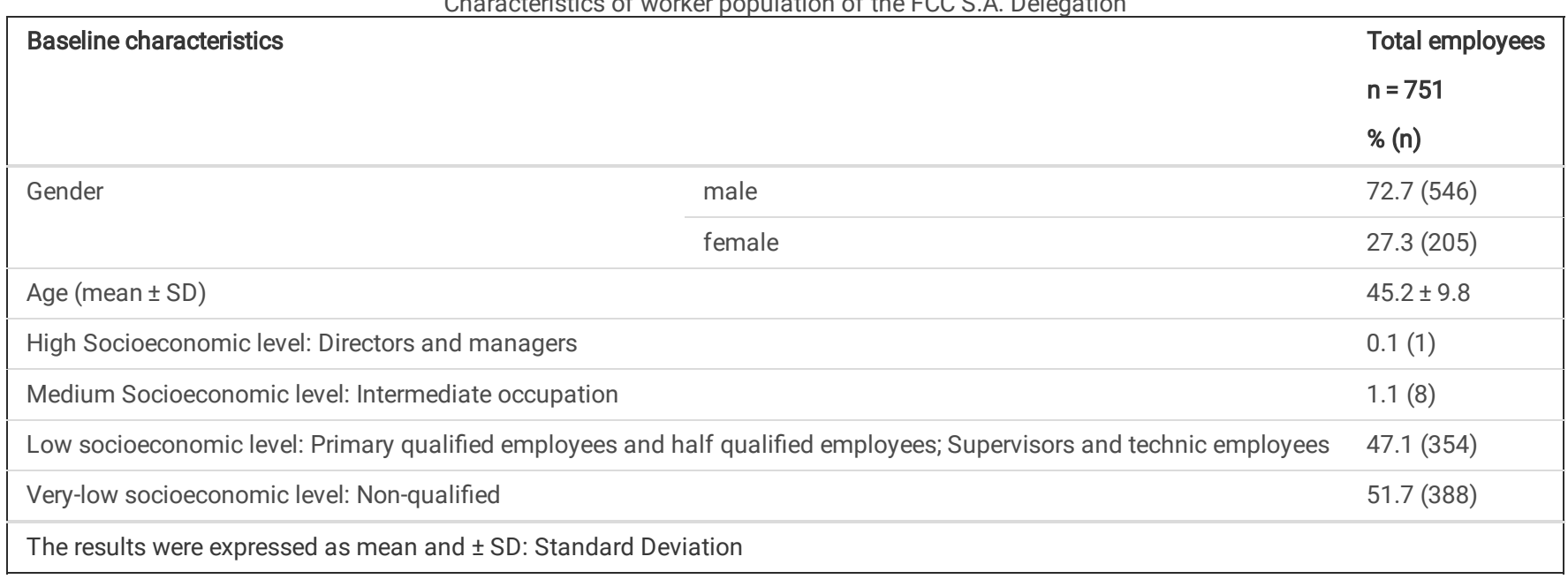

Table 2 shows the characteristics of employees depending on their intensity OPA, high OPA or low OPA. Almost half of the employees, $44.5 \%(n=334)$ were categorized as low OPA. A 54.6\% $(n=298)$ of males had a low OPA compared with only $17.5 \%(n=36)$ of females. 
Table 2

Categories of employees divided according to their intensity of the occupational physical activity (OPA)

\begin{tabular}{|c|c|c|c|}
\hline & & $\begin{array}{l}\text { Low OPA } 44.5 \% \mathrm{n}= \\
334\end{array}$ & $\begin{array}{l}\text { High OPA } 55.5 \% \mathrm{n}= \\
417\end{array}$ \\
\hline & & $\%(n)$ & $\%(n)$ \\
\hline \multirow[t]{2}{*}{ Gender } & male & $89.2(298)$ & $59.5(248)$ \\
\hline & female & $10.8(36)$ & $40.5(169)$ \\
\hline Age & $\begin{array}{l}y(\text { mean } \pm \\
\text { SD) }\end{array}$ & $45.2 \pm 9.8$ & $45.2 \pm 10.2$ \\
\hline \multirow{3}{*}{$\begin{array}{l}\text { Managers: administrative and commercial managers/production and specialized service } \\
\text { managers }\end{array}$} & male & $0.7(4)$ & \\
\hline & female & $5.4(11)$ & \\
\hline & total & $2(15)$ & \\
\hline \multirow[t]{3}{*}{ Drivers and mobile plant operators } & male & $32.6(178)$ & \\
\hline & female & $2.4(5)$ & \\
\hline & total & $24.4(183)$ & \\
\hline \multirow[t]{3}{*}{ Supervisor of operators and drivers } & male & $21.3(116)$ & \\
\hline & female & $9.8(20)$ & \\
\hline & total & $18.1(136)$ & \\
\hline \multirow[t]{3}{*}{ Cleaners and helpers } & male & & $2.2(12)$ \\
\hline & female & & $49.8(102)$ \\
\hline & total & & $15.2(114)$ \\
\hline \multirow[t]{3}{*}{ Plant and machine operators and assemblers } & male & & $43.2(236)$ \\
\hline & female & & $32.7(67)$ \\
\hline & total & & $40.4(303)$ \\
\hline \multicolumn{4}{|l|}{ OPA: Occupational physical activity - According to Compendium of Physical Activities[23] } \\
\hline \multicolumn{4}{|l|}{ Professional category: to the International Labour Organization[20] } \\
\hline
\end{tabular}

Table 3 showed the association between the high intensity of OPA and cardiovascular risk factors. Employees of male gender with high intensity of OPA had a significant negatively association with $\mathrm{BMI}(\mathrm{B}=-0.042, \mathrm{p}=0.003)$, WC $(\mathrm{B}:-0.027, \mathrm{p}<0.001)$, waist-hip ratio $(\mathrm{B}:-5.484, p<0.001)$ and cholesterol $(\mathrm{B}:-0.007, \mathrm{p}=$ 0.015); and triglycerides in blood ( $B:-0.003, p=0.025)$. Focus on employees of female gender with high intensity of OPA, had a significant positive association with blood pressure: SBP (B: 0.036, $p=0.005)$ and DBP $(B: 0.040, p=0.021)$.

In lifestyle parameters, only tobacco consumption was significantly positively associated with the high intensity of OPA in male employees $(B=0.394, p=$ 0.024). Other lifestyles such as LTPA or alcohol, consumption were not associated with the intensity of OPA. 
Table 3

Association between employees with high intensity OPA and cardiovascular risk factors.

\begin{tabular}{|c|c|c|c|c|c|c|}
\hline & $\begin{array}{l}\text { Total sa } \\
\mathrm{n}=751\end{array}$ & & $\begin{array}{l}\text { Male } \\
n=546\end{array}$ & & $\begin{array}{l}\text { Female } \\
\mathrm{n}=205\end{array}$ & \\
\hline & B & $p$-value & B & $p$-value & B & $p$-value \\
\hline BMI\# & -0.042 & 0.003 & -0.046 & 0.008 & 0.029 & 0.423 \\
\hline Systolic Blood Pressure\# & -0.005 & 0.167 & -0.002 & 0.677 & 0.036 & 0.005 \\
\hline Diastolic Blood Pressure ${ }^{\#}$ & -0.01 & 0.097 & -0.012 & 0.102 & 0.040 & 0.021 \\
\hline Waist circumference ${ }^{\#}$ & -0.027 & $<0.001$ & -0.020 & 0.003 & 0.017 & 0.242 \\
\hline Waist-hip ratio\# & -5.484 & $<0.001$ & -2.999 & 0.010 & 4.259 & 0.130 \\
\hline Glucose mg/dL" & -0.002 & 0.377 & -0.001 & 0.604 & -0.001 & 0.909 \\
\hline Cholesterol mg/dL" & -0.007 & 0.015 & -0.011 & 0.001 & 0.008 & 0.203 \\
\hline Triglycerides mg/dL $\#$ & -0.003 & 0.025 & -0.002 & 0.10 & 0.001 & 0.865 \\
\hline LTPA $^{*}$ & -0.431 & 0.057 & -0.214 & 0.407 & -0.963 & 0.074 \\
\hline Tobacco* & 0.210 & 0.163 & 0.394 & 0.024 & -0.026 & 0.945 \\
\hline Alcohol $^{*}$ & 0.292 & 0.691 & 0.477 & 0.534 & 19.662 & 1.000 \\
\hline
\end{tabular}

These risk factors are measured as associations: \#Logistic regression multivariate analysis and *Binary regression logistic analysis Bold $p<0.05$

Besides, table of additional file 2 showed the anthropometric, biochemical and lifestyle parameters of employees compared by their low or high intensity of OPA. Most of the results observed in Table 3 are reinforced in additional file 2, where males carried out the high intensity of OPA presented lower levels of BMI, WC, WHR, cholesterol, and higher consumption of tobacco, compared to employees carried out the low intensity of OPA. On the other hand, females carried out the high intensity of OPA presented higher levels of SBP and DBP compared to the low intensity of OPA females (additional file 2), results supported by association analysis presented in Table 3. Also, additional file 2 showed lower levels of OW and OB prevalence in the high intensity of OPA (69\%; $\mathrm{n}=171$ ) compared to the low intensity of OPA $(82.2 \% ; n=245), p<0.001$. Moreover, considering females and males together, employees carried out the high intensity of OPA presented lower percentages of diabetes mellitus $(3.5 \%, n=15$ vs. $7.5 \%, n=25 ; p=0.022)$ and metabolic syndrome $(1.7 \%, n=7$ vs. $4.2 \%, n=14 ; p=$ 0.045), compared with employees carried out the low intensity of OPA. In lifestyle parameters, specifically in high LTPA, there are no significant differences between low intensity of OPA vs high intensity of OPA $(14.4 \%, n=48$ vs. $9.8 \%, n=41 ; p=0.069)$.

\section{Discussion}

The present cross-sectional study, conducted in the FCC S.A. Delegation, showed that the high intensity of OPA was significantly negatively associated with cardiovascular risk factors in males, such as BMI, WC, waist-hip ratio, and cholesterol and triglycerides levels in the blood, suggesting better cardiovascular health. However, in males, the high intensity of OPA was positively associated with tobacco consumption. In females, the high intensity of OPA was significantly positively associated with blood pressure levels, contrarily suggesting poorer cardiovascular health.

The hypothesis of the present cross-sectional study, about high intensity of OPA could be associated with a detrimental in health status, in particular, in cardiovascular health [13]; and it is confirmed in female employees, due to negative association with blood pressure levels. A possible explanation in females cleaners, who in present study females represented the majority of type of job, the muscle contractions during manual handling could be associated with elevated blood pressures [13].

In the same way, 419 female cleaners from five hotels evaluated during $18 \mathrm{~h}$ including work and leisure time, showed an increased systolic blood pressure and pulse pressure, thus room cleaners were also associated with increase blood pressure [27]. Surprisingly, cleaners presented higher levels of SBP and DBP than other professional categories and considering the exposure to chemical products as a confounder factor such as chemical exposure was proposed as a key signaling mineralocorticoid a base of blood pressure control (Huang, Ye, \& Zhang, 2020).

Focus on LTPA, people have the time and frequency control of the free physical activity but the OPA intensity was difficult to control, depending on each job characteristics and working day. In a prospective cohort, lower LTPA was associated with an elevated risk of cardiovascular disease mortality events [28]. Recently, physical activity paradox has been defined as high OPA intensity increase the risk of mortality for cardiovascular events in men, whereas increasing the levels of physical activity is recommended for preventing cardiovascular events $[11,14]$ by LTPA as recommended to prevent cardiovascular disease [29].

Focus on WC, in our study population, low OPA intensity employees presented a high mean of WC, such as $98.0 \mathrm{~cm} \pm 13.8$ and $92.9 \mathrm{~cm} \pm 13.7$ in employees with high OPA intensity. Although the mean of WC, in men low OPA was $99.5( \pm 13.0) \mathrm{cm}$ while high OPA intensity was 96.0 ( \pm 13.4$) \mathrm{cm}$, and in women, low 
OPA was $85.47( \pm 14.6) \mathrm{cm}$ and $88.3( \pm 12.9) \mathrm{cm}$, was not superior to defined cut-off points [17].

In a Spanish cross-sectional study, conducted with 259,014 workers, aimed to associate metabolic syndrome with occupation and gender, demonstrated that metabolic syndrome was higher in blue collars females, such as cleaners than white collars such as administrative occupation [30]. These results were aligned with our results, due to our high OPA female population, majority cleaners (blue collar), presented higher blood pressure, one of the criteria of metabolic syndrome, than low OPA female population. While cross-sectional of Sanchez-Chaparro et al associated metabolic syndrome with occupational category, our present cross-sectional had one-step further because associated with the intensity of OPA related to the occupational category. Moreover, focus on the low intensity of OPA employees, the prevalence of overweight and obesity was higher than Spanish National data (18-65y) in 2017 [31]. Spanish working population presented a prevalence of overweight plus obesity of $56 \%$ in males and $39 \%$ in females, lower than $82.2 \%$ and $55.6 \%$ showed in the present cross-sectional study, respectively. So, workplace weight management programs could increase the engagement of employees [32]. However, from all results, one important aspect to consider is to design and implement different workplace interventions depending on the OPA intensity levels and gender of employees, to achieve a significant effect.

On the other hand, focusing on lifestyles, male employees with high OPA intensity presented a significantly higher prevalence and significant association of tobacco consumption compared to low OPA intensity employees. Most of the high intensity of OPA male employees of FCC S.A. Delegation developed tasks of their work outdoors, as street cleaners probably they have more access to smoke than the low OPA intensity employees.

Thus, not only to avoid smoking, a major cardiovascular risk factor, the intensity of OPA, type of job developed by employee and gender could be considered as key indicators to contemplate in the design of workplace programs to improve the cardiovascular health of employees.

Whereas for employees with low intensity of OPA, taking into account this activity could be considered as a sedentary lifestyle, acting as a major modifiable risk factor for cardiovascular disease [7, 33].The interventions to improve cardiovascular risk factors for males with high intensity of OPA should be tested because the evidence suggests that high OPA employees may not be a benefit for LTPA supporting caution should be in recommending exercise in the high intensity of OPA employees [34]. However, in workplace interventions directed to females with high intensity of OPA, it is suggested the effectiveness of lowering SBP by a single session per day in cleaners' females [35].

Therefore, from the evidence of the cardiovascular risk factors of employees, it could carry on actions to prevent cardiovascular disease at the workplace. Supporting the interventions, the workplace is a good environment to improve physical activity behaviors [36-38].

The present cross-sectional study had some limitations. Firstly, the study population included only one Delegation of one company, the FCC workers in Tarragona, whereas more participants of other FCC Delegations around all Spain could provide more information. Secondly, physical activity during the working time was assessed by International Physical Activity Questionnaire [19], and it was not calculated by an Actical accelerometer considered as the gold standard tool to evaluate physical activity $[19,39,40]$ due to implying higher costs for the company. Thirdly, disease variables such as percentage of employees with hypertension and cholesterol were based on the diagnosis of the family physician, and workers were medicated, for this reason, the mean of variables related to medicated employees (mean of blood pressure and mean of blood cholesterol) was misleading. Fourthly, OW and OB prevalence could act as a confounder because it is associated with high cardiovascular risk factors, and males with high OPA intensity levels showed a low percentage of OW and OB and less cardiovascular risk factors than males with low intensity of OPA. Fifthly, although this study had the appropriate sample size, it would be more interesting to include different companies to obtain a sample size with a higher diversity of employees, to be possible to improve the generalizability of the results obtained. Besides, males represented the huge part, the generalizability of our findings to female is limited, and it should include a higher percentage of females in future researches.

Furthermore, the study had some strengths, it included a huge sample size of employees with different OPA intensity categories. Moreover, the data obtained related to cardiovascular risk factors assessed in the workplace, are based on blood analysis, anthropometric measures, and validated questionnaires. The present cross-sectional study is the first study that investigated the workplace population categorizing the intensity levels of the OPA in Spain.

\section{Conclusion}

High intensity of OPA is associated with less cardiovascular risk factors in men, whereas women are associated with high levels of blood pressure, suggesting an influence of gender and work categories.

\section{List Of Abbreviations}

Occupational Physical Activity (OPA)

Fomento de Construcciones y Contratas S.A. (FCC S.A. Delegation)

Waist Circumference (WC)

Hip Circumference (HC)

Body Mass Index (BMI)

World Health Organization (WHO)

Leisure-Time Physical Activity (LTPA) 


\section{Declarations}

\section{ETHICS APPROVAL AND CONSENT TO PARTICIPATE}

All employers and employees $(n=751)$ have signed written informed consent. The program obtained the approval of the security and health committees of all company worksites and agreed and signed with the worksite unions, and the program is included in the collective bargaining agreement. The program design was approved and obtained a certificate of ethical approval from the Security and Health Committee of the FCC S.A. Delegation and the Catalan public administration (Subdirección General de Drogodependencias de la Agència de Salut Pública de Catalunya, Servicios Territoriales de Tarragona del Departamento de Trabajo). The clinical information was strictly confidential, following the organic law 17/1999, of 13 December about personal data protection L.O.P.D. All of the reference data for detection controls are collected in the medical service of the FCC S.A. Delegation.

\section{AUTHOR CONTRIBUTIONS}

MG-R, SA-B designed the study.

MG-R, SA-B conducted research (data collection).

MG-R, SA-B, EL, LT, RS provided essential materials.

MG-R, EL, LT analyzed data or performed statistical analysis.

MG-R, SA-B, EL, LT, RS drafted and revised the manuscript.

MG-R, SA-B, EL, LT, RS take primary responsibility for the study and the manuscript content.

MG-R, SA-B, EL, LT, RS read and approved the final draft of the manuscript.

\section{AVAILABILITY OF DATA AND MATERIAL}

The technical appendix, statistical code, and dataset are available from the corresponding authors upon request: elisabet.Ilaurado@urv.cat and lucia.tarro@urv.cat.

\section{COMPETING INTERESTS}

Authors declare no conflicts of interest.

\section{ACKNOWLEDGMENTS}

This study was supported by the FCC S.A. Delegation. We would like to express our gratitude to the staff and employers and the FCC S.A. Delegation.

\section{FUNDING DETAILS}

No funding was received for this study.

\section{References}

1. Burton J. Healthy Workplace Framework and Model: Background and Supporting Literature and Practice [Internet]. World Heal. Organ. 2010. Available from: http://www.ncbi.nlm.nih.gov/pubmed/17514926.

2. Hutchinson AD, Wilson C. Improving nutrition and physical activity in the workplace: A meta-analysis of intervention studies. Health Promot Int. 2012;27:238-49.

3. Organisation for Economic Co-operation and Development. OECD employment: hours worked. [Internet]. 2018. Available from: data.oecd.org/emp/hoursworked.htm.

4. Lee IM, Shiroma EJ, Lobelo F, Puska P, Blair SN, Katzmarzyk PT, et al. Effect of physical inactivity on major non-communicable diseases worldwide: An analysis of burden of disease and life expectancy. Lancet Lancet Publishing Group. 2012;380:219-29.

5. Durstine JL, Gordon B, Wang Z, Luo X. Chronic disease and the link to physical activity. J. Sport Heal. Sci. Elsevier; 2013. p. 3-11.

6. Matthews CE, George SM, Moore SC, Bowles HR, Blair A, Park Y, et al. Amount of time spent in sedentary behaviors and cause-specific mortality in US adults 1-3. Am J Clin Nutr. 2012;95:437-45.

7. Teramoto M, Moonie S, Cross CL, Chino M, Alpert PT. Association of Leisure-Time Physical Activity to Cardiovascular Disease Prevalence in Relation to Smoking among Adult Nevadans. PLoS One. 2015;1-9.

8. Debette S, Seshadri S. Risk factors for cerebrovascular disease and stroke. Press OU, editor. 2016. 
9. Wang C, De Roos A, Fujishiro K, Allison M, Wallace R, Seguin R, et al. Occupational Physical Activity and Coronary Heart Disease in Women's Health Initiative Observational Study. J Gerontol A Biol Sci Med Sci. 2018;24.

10. Hu G, Sarti C, Jousilahti P, Silventoinen K, Barengo NC, Tuomilehto J. Leisure time, occupational, and commuting physical activity and the risk of stroke. Stroke. 2005;36:1994-9.

11. Coenen P, Huysmans MA, Holtermann A, Krause N, van Mechelen W, Straker LM, et al. Do highly physically active workers die early? A systematic review with meta-analysis of data from 193696 participants. Br J Sports Med. 2018.

12. Krause N, Sandler DP, Hall C, Ritz B, Heck JE, Chen H. Occupational and leisure-time physical activity differentially predict 6-year incidence of stroke and transient ischemic attack in women. Scand J Work Environ Health. 2018;0-13.

13. Balla Abdalla T, Rutkofsky I, Syeda J, Saghir Z, Muhammad A. Occupational Physical Activity in Young Adults and Stroke: Was It Due to My Job? Cureus. 2018;28:e3217.

14. Holtermann A, Krause N, Van Der Beek AJ, Straker L. The physical activity paradox: Six reasons why occupational physical activity (OPA) does not confer the cardiovascular health benefits that leisure time physical activity does. Br J Sports Med. 2018;52:149-50.

15. Strobe statement. STROBE checklists. Strengthening the reporting of observational studies in epidemiology. [Internet]. 2009. Available from: https://www.strobe-statement.org/index.php?id=available-checklists.

16. Lohman T. Anthropometric standardization reference manual. Champaign III.: Human Kinetics Books; 1991.

17. Sociedad Española para el Estudio de la Obesidad (SEEDO). Consenso SEEDO'2000 para la evaluación del sobrepeso y la obesidad y el establecimiento de criterios de intervención terapéutica. Med Clínica [Internet]. 2000;587-97. Available from:

https://seedo.es/images/site/documentacionConsenso/Consenso_SEEDO_2000.pdf.

18. WHO Expert. Waist Circumference and Waist-Hip Ratio Report of a WHO Expert Consultation. 2011.

19. Tomioka K, Iwamoto J, Saeki K, Okamoto N. Reliability and Validity of the International Physical Activity Questionnaire (IPAQ) in Elderly Adults: The Fujiwara-kyo Study. 2011;21:459-65.

20. International Labour Organization. International Standard Classification of Occupation. ISCO-08 Part 2: Classification Structure. [Internet]. 2017. Available from: http://www.ilo.org/public/english/bureau/stat/isco/isco08/. Accessed: 4\%0ASeptember 2018.

21. Magrinyà $P$, Mompart A, Medina A, Schiaffino A, Alcañiz $M$, Guillén $M$, et al. Caracterització de la població, de la mostra i metodologia de l'Enquesta de salut de Catalunya [Internet]. General. Catalunya. Dep. Salut. 2017. Available from: http://salutweb.gencat.cat/web/.content/_departament/estadistiquessanitaries/enquestes/Enquesta-de-salut-de-Catalunya/Resultats-de-lenquesta-de-salut-de-Catalunya/documents/metodologia_enquesta2016.pdf.

22. Domingo-Salvany A, Bacigalupe A, Carrasco J, Espelt A, Ferrando J, Borrell C. Propuestas de clase social neoweberiana y neomarxista a partir de la Clasificación Nacional de Ocupaciones 2011. Gac Sanit. 2013;27:263-72.

23. Ainsworth BE, Haskell WL, Herrmann SD, Meckes N, Bassett DR, Tudor-Locke C, et al. Compendium of Physical Activities: A Second Update of Codes and MET Values. Med Sci Sport Exerc [Internet]. 2011 [cited 2019 Nov 27];43:1575-81. Available from: http://prevention.sph.sc.edu/tools.

24. Kasper DL, Fauci AS, Hauser SL, Longo DL, Jameson JL, Loscalzo J. Chapter 118: Metabolic Syndrome. Harrison's Princ Intern Med. 2015.

25. Instituto Nacional de Estadística. (National Statistics Institute). 2019.

26. Sánchez-Chaparro MA, Román-García J, Calvo-Bonacho E, Gómez-Larios T, Fernández-Meseguer A, Sáinz-Gutiérrez JC, et al. Prevalence of Cardiovascular Risk Factors in the Spanish Working Population. Rev Española Cardiol (English Ed. 2006;59:421-30.

27. Feaster $M$, Krause N. Job strain associated with increases in ambulatory blood and pulse pressure during and after work hours among female hotel room cleaners. Am J Ind Med. 2018;61:492-503.

28. Stamatakis E, Gale J, Bauman A, Ekelund U, Hamer M, Ding D. Sitting Time, Physical Activity, and Risk of Mortality in Adults. J Am Coll Cardiol. 2019;73:2062-72.

29. Aggio D, Papachristou E, Papacosta O, Lennon LT, Ash S, Whincup P, et al. Trajectories of physical activity from midlife to old age and associations with subsequent cardiovascular disease and all-cause mortality. J Epidemiol Community Health. 2019;1-7.

30. Sánchez-Chaparro M, Calvo-Bonacho E, González-Quintela A, Fernández-Labandera C, Cabrera M, Sáinz J, et al. Occupation-related differences in the prevalence of metabolic syndrome. Diabetes Care. 2008;31:1884-5.

31. Instituto Nacional de Estádistica (Spain). Determinantes de salud (sobrepeso, consumo de fruta y verdura, tipo de lactancia, actividad física) [Internet]. 2018. Available from: http://www.ine.es/ss/Satellite?

$\mathrm{L}=$ es_ES\&C=INESeccion_C\&cid=1259926457058\&p=1254735110672\&pagename=ProductosYServicios\%2FPYSLayout\&param1=PYSDetalle\&param3=12

32. Clancy S, Stroo M, Schoenfisch A, Dabrera T, Østbye T. Barriers to Engagement in a Workplace Weight Management Program: A Qualitative Study. Am J Heal Promot. 2018;32:763-70.

33. Young DR, Hivert MF, Alhassan S, Camhi SM, Ferguson JF, Katzmarzyk PT, et al. Sedentary behavior and cardiovascular morbidity and mortality: A science advisory from the American Heart Association. Circulation. 2016;134:e262-79.

34. Lee S, Moon M, Choi W, Jang T. Exercise and cardiovascular load in workers with high occupational physical activity. Arch Env Occup Heal. 2019;28:1-7.

35. 10.1007/s00421-017-3773-z

Lund Rasmussen C, Nielsen L, Linander Henriksen M, Søgaard K, Krustrup P, Holtermann A, et al. Acute effect on ambulatory blood pressure from aerobic exercise: a randomised cross-over study among female cleaners. Eur J Appl Physiol [Internet]. Springer Berlin Heidelberg; 2018;118:331-8. Available from: http://dx.doi.org/10.1007/s00421-017-3773-z.

36. Wahlström V, Bergman F, Öhberg F, Eskilsson T, Olsson T, Järvholm LS. Effects of a multicomponent physical activity promoting program on sedentary behavior, physical activity and body measures: a longitudinal study in different office types. Scand J Work Environ Health. 2019;0-12.

Page 9/10 
37. Genin PM, Dessenne P, Finaud J, Pereira B, Dutheil F, Thivel D, et al. Effect of Work-Related Sedentary Time on Overall Health Profile in Active vs. Inactive Office Workers. Front Public Heal. 2018;6:1-8.

38. Reed JL, Prince SA, Elliott CG, Mullen KA, Tulloch HE, Hiremath S, et al. Impact of workplace physical activity interventions on physical activity and cardiometabolic health among working-age women. Circ Cardiovasc Qual Outcomes. 2017;10.

39. Steeves JA, Tudor-Locke C, Murphy RA, King GA, Fitzhugh EC, Bassett DR, et al. Daily physical activity by occupational classification in US adults: NHANES 2005-2006. J Phys Act Heal. 2018;15:900-11.

40. Griffiths LJ, Sera F, Cortina-Borja M, Law C, Ness A, Dezateux C. Objectively measured physical activity and sedentary time: cross-sectional and prospective associations with adiposity in the Millennium Cohort Study. BMJ Open. 2016;6:e010366.

\section{Additional File}

Additional file 1. STROBE Statement-Checklist of items that should be included in reports of cross-sectional studies

Additional file 2. Comparison of cardiovascular risk factors depending on low intensity OPA vs high intensity OPA employees

\section{Supplementary Files}

This is a list of supplementary files associated with this preprint. Click to download.

- Additionalfile2..docx

- Additionalfile2..docx

- Additionalfile2..docx

- Additionalfile1.STROBEchecklistcrosssectional.doc

- Additionalfile1.STROBEchecklistcrosssectional.doc

- Additionalfile1.STROBEchecklistcrosssectional.doc 